\title{
Design and Performance of Heat Pipe Air-Conditioning Based on Latent Heat of Water Evaporation
}

\author{
Jinhui ZHAO a,b Yifan BU, ${ }^{\mathrm{a}}$, Lijun ZHANG ${ }^{\mathrm{a}, 1}$ \\ a School of Chemical Engineering, Zhengzhou University, Zhengzhou, Henan, China \\ ${ }^{\mathrm{b}}$ China Petrochemical Corporation Luoyang Branch, Luoyang, Henan, China
}

\begin{abstract}
This paper proposes a scheme for creating a low-pressure environment to evaporate a large amount of water, using the latent heat of water evaporation for cooling, designing and building a test bench for a heat pipe air conditioning system, and testing the working performance of a negative pressure evaporating heat pipe air conditioner at $30-85^{\circ} \mathrm{C}$. COMSOL Multiphysics Establish a fluid heat transfer model to analyze internal heat transfer. Under the design condition of $40^{\circ} \mathrm{C}$, the EER is 2.1 and the cooling capacity is $298 \mathrm{~W}$. The experimental data and results show that the EER of the system in the high-efficiency working range of $50-75^{\circ} \mathrm{C}$ is 2.5 , the maximum cooling capacity is $376 \mathrm{~W}$, and the EER in the actual application temperature range of $30-40^{\circ} \mathrm{C}$ is 1.4 , and the cooling capacity is $221.6 \mathrm{~W}$. Basically reached the design index and can run stably.
\end{abstract}

Keywords. Latent heat of water evaporation, numerical simulation, negative pressure evaporation, gravity heat pipe.

\section{Introduction}

The Freon refrigerants used in refrigeration units have serious damage to the ozone layer, and the development of refrigerant replacement technology has not yet been improved. The application research and promotion of natural refrigerants are actively promoted.[1]As a natural refrigerant, water is not only low in cost and easy to obtain, but also environmentally friendly. In practical application, evaporative cooling technology can be used to make a large amount of water evaporate to achieve the cooling effect.

Evaporative cooling technology is an energy-saving and environmental friendly refrigeration method.Many scholars have done a lot of research.Yang[2] et al. carried out the numerical simulation of the air distribution in the evaporative cooling air conditioning room, and pointed out that the evaporative cooling air conditioner can meet the regulation requirements of human thermal comfort..Zheng[3] et al. verified the feasibility of testing the performance of evaporative cooling air-conditioning through numerical simulation.Guo[4] etal. studied the influence of wall wettability, length of evaporation heat transfer part, fluid velocity, ambient humidity and evaporation rate on the cooling effect.Zhang[5-6] et al. performed temperature field

${ }^{1}$ Corresponding Author,School of Chemical Engineering, Zhengzhou University, Zhengzhou 450000 Henan, China; E-mail: zhaojinhui@zzu.edu.cn. 
and flow field simulations on indirect evaporative cooling heat exchangers, and the results showed that air wind speed and inlet dry bulb temperature have a great influence on cooling efficiency. F.Fakhrabadi[7] et al. introduced an optimization design method of indirect evaporative cooling regenerative heat exchanger.

In terms of the application of evaporative cooling air conditioning, Ji[8] et al. applied indirect evaporative cooling to fresh air precooling of air conditioning, and the results showed that indirect evaporative cooling has great potential in fresh air precooling.Zhang[9] applied the evaporative refrigeration and air conditioning system to the college student activity center through indirect evaporation.Li[10] et al. developed the energy-saving evaporative refrigeration technology with full fresh air for household air conditioning based on the principle of direct water evaporative refrigeration.Wang[11] et al. developed the heat pipe air conditioning system in the machine room, which utilizes natural cooling source to a certain extent and significantly improves energy efficiency compared with traditional air conditioning.Deng[12] et al. developed a heat exchanger using heat pipe to transfer the cold amount generated during the evaporation of liquefied natural gas to the air conditioning system of automobiles.Xing[13] et al. analyzed various forms and energy-saving effects of evaporative cooling technology applied in air conditioning and pointed out that evaporative cooling technology has broad application prospects in both eastern and western China.

Both direct and indirect evaporation are carried out under atmospheric pressure $[14,15]$. The saturation temperature of water at $1.7 \mathrm{kPa}$ pressure is only $15^{\circ} \mathrm{C}$. This paper proposes a method that creates a low-pressure environment with vacuum pump to promote the evaporation of water to produce cold volume, and then uses heat pipe as heat exchange equipment to transfer cold volume to air.The experimental platform of heat pipe air conditioning system based on latent heat of water evaporation was built, and the performance of refrigerating machine under different working conditions was tested. The operating characteristics of heat pipe air conditioning system based on latent heat of water evaporation were explored through numerical simulation.

\section{Design}

\subsection{Experimental System Design}

The experimental design process of the refrigeration system is as follows:

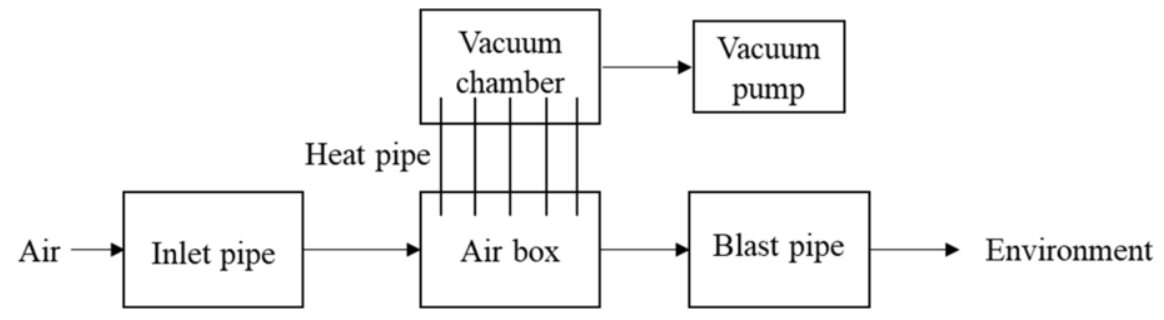

Figure 1. Flow chart of the system

As shown in figure 1, after being filtered and dried, the outside air is heated in the inlet pipe to create different experimental conditions. The hot air exchanges heat with 
the heat pipe inside the air box.The cold air after heat exchange is discharged into the room through the blast pipe. The heat transfer fluid in the heat pipe evaporates and rises, and the heat transfer fluid flows back after the heat exchange between the condensation section of the heat pipe and the water in the vacuum chamber. The water in the vacuum box evaporates and absorbs heat continuously under the action of the vacuum pump to keep the temperature in the vacuum box low.

\subsection{Composition of Experimental Components}

The basic structure of heat pipe air conditioning system based on latent heat of water evaporation is shown in figure 2

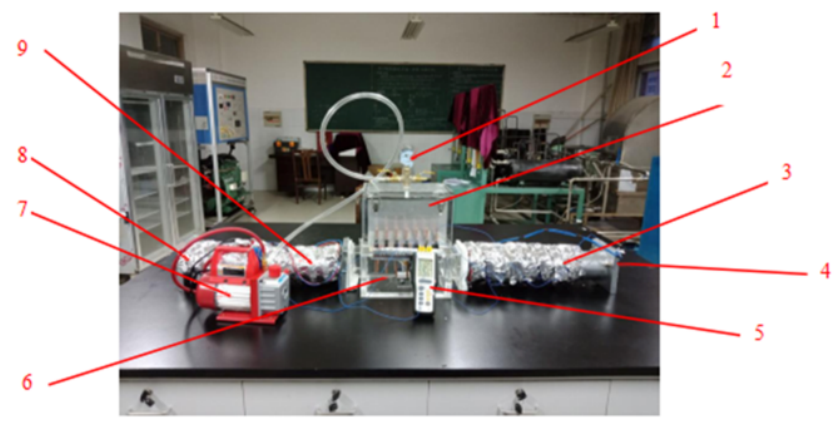

1 Pressure gauge;2 Vacuum chamber;3 Inlet pipe;4 Dry filter box;

5 Thermodetector;6 Air box;7 Vacuum pump;8 Axial flow fan;9 Blast pipe

Figure 2. Prototype of the refrigeration and air conditioning system

As shown in figure 2,the dry filter box is installed at the air inlet.The air inlet pipe and blast pipe are connected with the air box.The condensing section of gravity heat pipe is in the vacuum chamber, and the evaporation section is in the air box.The length of condensing section and evaporation section is the same.The heat pipe is made of brass with a width of $6 \mathrm{~mm}$, a thickness of $3 \mathrm{~mm}$ and a length of $180 \mathrm{~mm}$. It is a gravity type heat pipe without a wick. The internal heat conduction working medium is ethanol, and the evaporation temperature is $20^{\circ} \mathrm{C}$. The vacuum chamber is connected with the vacuum pump through a rubber tube, and a pressure gauge is installed on the cover of the vacuum chamber.The axial flow fan is installed at the outlet of the blast pipe; the thermometer is connected with thermocouple, and four temperature measuring points are set to monitor the laboratory temperature, inlet air temperature, surface temperature of heat pipe and supply air temperature. The inlet air temperature measuring point is set at the outlet center of the inlet pipe to measure the temperature of hot air entering the air box; the measuring point of the outlet air temperature is set at the center of the outlet of the air box to measure the air temperature after cooling; the measuring point of the surface temperature of the heat pipe is set at the middle section of the heat pipe on the side of the air box.

\section{Design Calculation}

The experimental design conditions are as follows: the wind speed is $1.8 \mathrm{~m} / \mathrm{s}$, the axial-flow fan with the power of $7 \mathrm{~W}$ is selected; The air duct is made of round 
galvanized steel with an inner diameter of $100 \mathrm{~mm}$ and a length of $500 \mathrm{~mm}$; The air duct is made of round galvanized steel with an inner diameter of $100 \mathrm{~mm}$ and a length of $500 \mathrm{~mm}$; the air temperature entering the air box is $40^{\circ} \mathrm{C}$, the air supply temperature is $22^{\circ} \mathrm{C}$, and the water evaporation pressure is $1.7 \mathrm{kPa}$. Calculate the following physical quantities:

(1) Cooling load of cooling system

$$
\begin{gathered}
Q_{0}=q_{m} c_{p} \Delta t \\
q_{m}=\rho v \pi d^{2} / 4
\end{gathered}
$$

$v$ is the wind speed,d is the diameter of the air duct. The cooling load of the cooling system is $298 \mathrm{~W}$ by substituting it into the formula.

(2) Water evaporation per unit time $\mathrm{kj} / \mathrm{kg}$.

Under the pressure of $1.7 \mathrm{kPa}$, the latent heat of vaporization of water is 2465.1

$$
\Delta M=Q_{0} / r
$$

The evaporation mass of water per unit time is obtained by substituting it into the formula. $\Delta \mathrm{M}=0.00012 \mathrm{~kg}$.

According to the formula

$$
\Delta V=\Delta M / \rho
$$

Under the pressure of $1.7 \mathrm{kPa}$, The density of water vapor is 0.0097 $\mathrm{kg} / \mathrm{m}^{3} . \Delta \mathrm{V}=12.3 \mathrm{~L} / \mathrm{s}$.

Single stage RM-1 vacuum pump is selected.

(3) The numbers of heat pipe

The experimental correlation of the flow across the pipe is as follows:

$$
\begin{aligned}
& N u=C \operatorname{Re}^{n} \operatorname{Pr}^{1 / 3} \\
& \operatorname{Re}=\frac{u l}{v}=1208
\end{aligned}
$$

$C$ is coefficient of correction; Re is Reynolds number; $P r$ is Prandtl number; $u$ is fluid velocity; $v$ is kinematic viscosity; $l$ is characteristic length.

The heat pipe is of flat structure, The flow of air around the heat pipe can be approximated as a flow across a vertical plate. $C=0.228 ; n=0.731 ; \operatorname{Pr}=0.701 . t_{m}=$ $\left(t_{w}+t_{f}\right) / 2=31^{\circ} \mathrm{C}, N u=100.86$.

The definition formula of Nusselt number is as follows:

$$
N u=h l / \lambda
$$


Heat transfer coefficient of heat pipe: $h=897 \mathrm{~W} /\left(\mathrm{m}^{2} \cdot \mathrm{k}\right)$. The length of condensation section and evaporation section of heat pipe is equal.Heat transfer between evaporation section and air.According to Newton's cooling formula,the heat transfer capacity of a single heat pipe is as follows:

$$
q=h S\left(t_{w}-t_{f}\right)=17.44 \mathrm{~W}
$$

Number of heat pipes selected: $N=Q_{0} / q=17$, Considering the actual shape of the equipment, 21 heat pipes were installed.The heat pipes are arranged in three rows and seven columns, with a horizontal spacing of $27.5 \mathrm{~mm}$ and a longitudinal spacing of $50 \mathrm{~mm}$.

According to the design conditions, the EER of the system is 2.1, and the cooling capacity is $298 \mathrm{~W}$.

\section{Experimental Analysis}

In order to test whether the refrigerator can achieve the refrigeration effect and working performance under the design condition, the $500 \mathrm{~W}$ electric heating pipe is used as the heat source to provide hot air at different temperatures. The air supply temperatures when the refrigerator is running and not running are recorded. The refrigeration capacity and energy efficiency ratio of the system are calculated according to the experimental data.

The environmental temperature measured by thermocouple thermometer is $21.5^{\circ} \mathrm{C}$, and the experimental data are shown in table 1 and table 2.

Table 1. Experimental data sheet of temperature in the system when the refrigerator is not running

\begin{tabular}{ccc}
\hline Supply air temperature $\mathbf{T}_{\mathbf{1}}\left({ }^{\circ} \mathbf{C}\right)$ & $\begin{array}{c}\text { Inlet air temperature } \mathbf{T}_{\mathbf{3}} \\
\left({ }^{\circ} \mathbf{C}\right)\end{array}$ & Ambient temperature $\mathbf{T}_{\mathbf{4}}\left({ }^{\circ} \mathbf{C}\right)$ \\
\hline 26.9 & 30.0 & 21.5 \\
30.0 & 35.0 & 21.5 \\
33.4 & 40.0 & 21.5 \\
37 & 45.0 & 21.5 \\
40.0 & 50.0 & 21.5 \\
42.7 & 55.0 & 21.5 \\
45.5 & 60.0 & 21.5 \\
47.4 & 65.0 & 21.5 \\
50.5 & 70.0 & 21.5 \\
55.5 & 75.0 & 21.5 \\
56.2 & 80.0 & 21.5 \\
56.3 & 85.0 & 21.5 \\
\hline
\end{tabular}

The cooling capacity and energy consumption ratio under different inlet air temperature are calculated by the formula, and the most efficient working range is determined.The cooling capacity and energy consumption ratio of the system are calculated as follows:

The cooling capacity of the system:

$$
\Delta q=q_{m} c_{p}\left(t_{h}-t_{l}\right)
$$


Table 2. Experimental data sheet of temperature in the system of the system when the refrigerator is running (The evaporation pressure is $0.0017 \mathrm{Mpa}$ )

\begin{tabular}{cccc}
\hline $\begin{array}{c}\text { Supply air } \\
\text { temperature } \\
\mathbf{T}_{\mathbf{1}}\left({ }^{\circ} \mathbf{C}\right)\end{array}$ & $\begin{array}{c}\text { Surface temperature } \\
\text { of heat pipe } \mathbf{T}_{\mathbf{2}}\left({ }^{\circ} \mathbf{C}\right)\end{array}$ & $\begin{array}{c}\text { Inlet air temperature } \\
\mathbf{T}_{\mathbf{3}}\left({ }^{\circ} \mathbf{C}\right)\end{array}$ & $\begin{array}{c}\text { Ambient temperature } \\
\mathbf{T}_{\mathbf{4}}\left({ }^{\circ} \mathbf{C}\right)\end{array}$ \\
\hline 24.0 & 20.9 & 30.0 & 21.5 \\
26.0 & 20.9 & 35.0 & 21.5 \\
28.0 & 21.5 & 40.0 & 21.5 \\
30.3 & 22.1 & 45.0 & 21.5 \\
31.6 & 22.6 & 50.0 & 21.5 \\
35.0 & 23.5 & 55.0 & 21.5 \\
36.6 & 24.2 & 60.0 & 21.5 \\
38.8 & 24.9 & 65.0 & 21.5 \\
40.2 & 25.3 & 70.0 & 21.5 \\
45.0 & 26.8 & 75.0 & 21.5 \\
47.0 & 27.9 & 80.0 & 21.5 \\
49.0 & 28.5 & 85.0 & 21.5 \\
\hline
\end{tabular}

The energy consumption ratio of the system:

$$
E E R=\frac{\Delta q}{W}
$$

$q_{m}$ is the mass flow rate of air; $c_{p}$ is the specific heat capacity of air at constant pressure; $t_{h}$ is the air supply temperature when the refrigerator is running; $t_{l}$ is the air supply temperature when the refrigerator is not running; $W$ is the power consumption of the refrigeration system, and the vacuum pump and fan are the power consumption equipment.

Taking the experimental data into the above formula, the relationship between the surface temperature of the heat pipe and the inlet air temperature is obtained as shown in figure 3, the change of the cooling capacity of the system with the inlet air temperature is shown in figure 4 , and the change of the system energy consumption ratio with the inlet air temperature is shown in figure 5 .

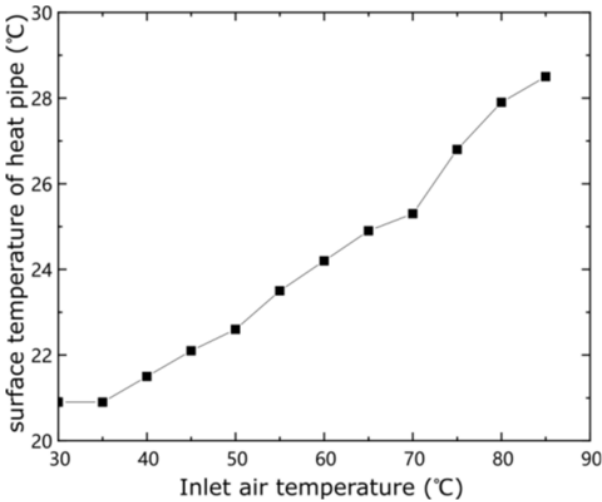

Figure 3. Relationship diagram of surface temperature of heat pipe and inlet air temperature

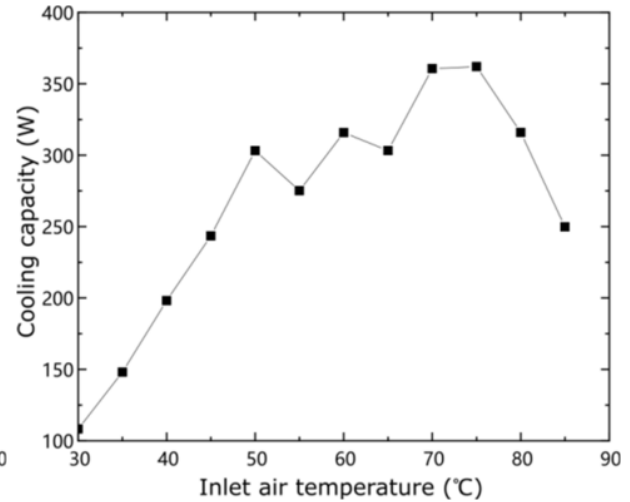

Figure 4. Relationship diagram of system cooling capacity and inlet air temperature 


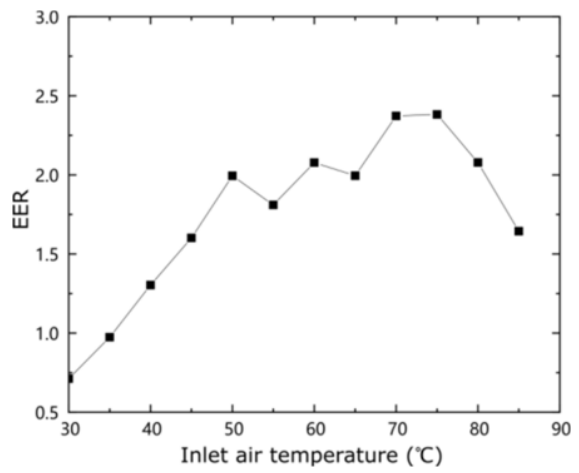

Figure 5. Relationship diagram of the system EER and inlet air temperature

As shown in figure 4 and figure 5, When the inlet air temperature is between $50^{\circ} \mathrm{C}$ and $75^{\circ} \mathrm{C}$, the cooling capacity and energy efficiency ratio are relatively high, and the system is in the high efficiency working range in this temperature range.The maximum energy efficiency ratio is 2.5.The actual application temperature range of the refrigerator is between $30^{\circ} \mathrm{Cand} 40^{\circ} \mathrm{C}$, the refrigerating capacity and EER increase with the increase of the inlet air temperature in this range. When the inlet air temperature reaches the design temperature of $40^{\circ} \mathrm{C}$, the EER of this system is 1.3 and the cooling capacity is $198 \mathrm{~W}$.

As shown in figure 3 , the surface temperature of heat pipe increases with the increase of inlet air temperature. There are two reasons: 1.The vacuum pump can not extract the water vapor in the vacuum box in time, so the pressure in the vacuum box increases, which reduces the evaporation rate of water. The heat introduced into the vacuum box by the heat pipe becomes the sensible heat of water, which makes the water temperature rise. 2. The cooling capacity of the evaporation section of the heat pipe is limited. With the increase of the inlet air temperature, the evaporation cooling capacity of the water in the vacuum box gradually reaches the limit, which makes the surface temperature of the evaporation section of the hot section increase gradually.

\section{Numerical Simulation}

In order to study the heat transfer between heat pipe and air, the mathematical model of heat pipe air conditioning system based on latent heat of water evaporation was established according to the experimental conditions, and the fluid heat transfer simulation was carried out.

\subsection{Physical Model}

As shown in figure 6,In order to simplify the model and maintain high simulation accuracy, the model size is determined according to the actual size. The length of the air box is $260 \mathrm{~mm}$, the width of the air box is $160 \mathrm{~mm}$, the height of the air box is $160 \mathrm{~mm}$. The left and right ends are the air inlet and outlet, and the inlet and outlet section is a square with side length of $120 \mathrm{~mm}$. There are 21 heat pipes standing on the bottom of the bellows. The arrangement is 3 rows and 4 columns. The physical model is meshed, and the number of meshes is 40775 , which meets the calculation requirements 
after grid independence verification.

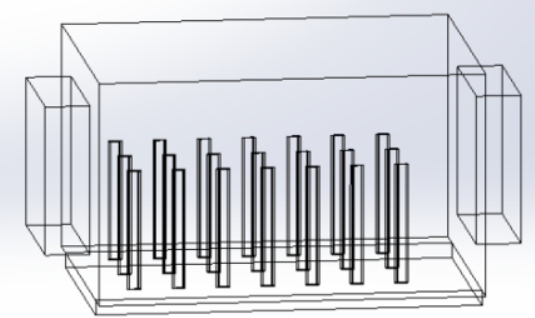

Figure 6. Physical model of the bellows

\subsection{Mathematical Model}

According to thermodynamics and fluid mechanics, a heat transfer-forced convection model is constructed. Under stable conditions, the heat dissipation rate of the air is equal to the thermal conductivity of the heat pipe. The heat transfer of the heat pipe and the air are calculated separately, and the flow field and the thermal field are coupled.

(1) According to the law of thermodynamics, the governing equation of solid heat transfer can be obtained:

$$
\begin{gathered}
\rho C_{p} \mathbf{u} \bullet \nabla T-\nabla \bullet q=Q+Q_{\text {ted }} \\
q=-k \nabla T
\end{gathered}
$$

$\nabla:$ Hamilton operator; $\mathrm{k}$ :Thermal conductivity, $\mathrm{W} /(\mathrm{m} \bullet \mathrm{K})$; $\mathrm{Q}_{\text {ted }}:$ Heat source, $\mathrm{W} / \mathrm{m}$;

(2) The governing equation of fluid heat transfer is obtained:

$$
\begin{gathered}
\rho C_{p} \mathbf{u} \bullet \nabla T-\nabla \bullet q=Q+Q_{\text {ted }}+Q_{p} \\
q=-k \nabla T
\end{gathered}
$$

(3) The governing equation of air flow is obtained:

$$
\begin{gathered}
\rho(\boldsymbol{u} \nabla) \boldsymbol{u}=\nabla\left\{-p \mathbf{I}+\mu\left[\nabla \boldsymbol{u}+(\nabla \boldsymbol{u})^{\mathrm{T}}\right]-2 / 3 \mu(\nabla \boldsymbol{u}) \boldsymbol{\}}+\mathbf{F}\right. \\
\nabla(\rho \boldsymbol{u})=0
\end{gathered}
$$

$p$ :Fluid stress tensor , $\mathrm{Pa} ; /$ : Deformation tensor , $\mathrm{Pa} ; \mathbf{F}$ :Fluid volume force , N/m $\mathrm{m}^{3}$; $\mu$ :dynamic viscosity, $\mathrm{Pa} \cdot \mathrm{s}$.

\subsection{Boundary Condition Setting}

The inlet air temperature and the surface temperature of the heat pipe are set to $40{ }^{\circ} \mathrm{C}$ 
and $20{ }^{\circ} \mathrm{C}$ respectively, and the air inside the bellows is defined to participate in the heat conduction calculation. In terms of flow field, the air supply speed is $1.4 \mathrm{~m} / \mathrm{s}$, the inlet length is $1 \mathrm{~m}$, the outlet pressure is 0 , and the backflow is restrained. The non isothermal flow coupling interface is used to calculate the thermal field and flow field.

\subsection{Result Analysis}

The temperature distribution and flow field distribution of the wind box are shown in figure 7 and figure 8 respectively.

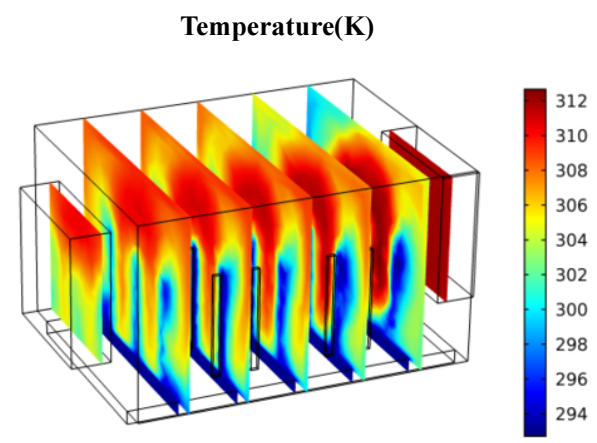

Figure 7. Temperature distribution of bellows

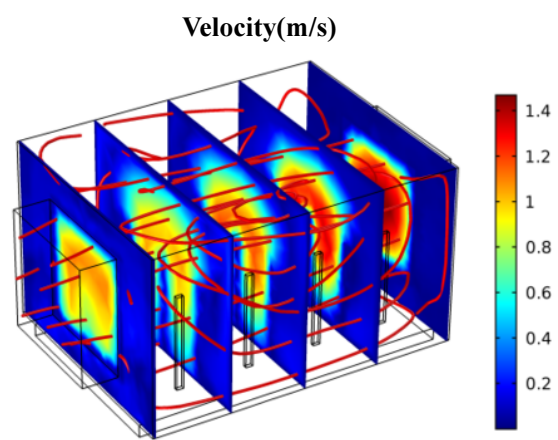

Figure 8. Flow field distribution of bellows

When the air flows in the wind box, the air temperature is significantly reduced. After calculation, the average temperature of the air outlet is $29.35{ }^{\circ} \mathrm{C}$. It can be seen from figure 7 that the temperature distribution is layered from top to bottom along the heat pipe, and the temperature difference is obvious. It can be seen from figure 8 that the air flow presents a trend of fast center and slow surroundings. Judging by the streamline and slice color, the internal flow field is laminar, and there is only a small swirling flow near the entrance and exit. When the flow field is laminar, the temperature of the air around the wall of the heat pipe is lower. The farther away from the wall of the heat pipe, the higher the temperature of the air, and air is a non-benign conductor of heat. The laminar flow deteriorates the heat transfer between the heat pipe and the air, resulting in a large temperature difference in the wind box, obvious stratification, and a high average outlet temperature.

The simulation results show that when the inlet air temperature is set to $40^{\circ} \mathrm{C}$, the average air outlet temperature of the air conditioner is $29.35^{\circ} \mathrm{C}$. The experimental data shows that when the inlet air temperature is controlled to $40^{\circ} \mathrm{C}$, the supply air temperature is $28^{\circ} \mathrm{C}$.when both the relative error was within $5 \%$, the reliability of the numerical simulation model can be confirmed.Therefore, it can be considered that the model can effectively simulate the working state of the refrigerator.

Experimental data show that with the change of the air inlet temperature, the cooling capacity and energy efficiency ratio change constantly. The high-efficiency working range of the refrigerator is $50 \sim 75^{\circ} \mathrm{C}$, and the maximum energy efficiency ratio can reach 2.5 when the refrigerator is running. The simulation results show that the air low temperature part increases gradually when the air flows in the air box.The temperature is distributed in layers, and the main stream is laminar flow, and only a small swirl exists in the edge area, which makes the heat transfer between the heat pipe 
and air poor.Analyzing the experimental data and simulation results: 1) laminar flow is the main reason for the poor heat exchange effect in the air box;2)As the inlet air temperature continues to increase, the evaporation rate of water vapor in the vacuum box increases, but the vacuum pump cannot The water vapor is sent out of the vacuum box in time, resulting in insufficient vacuum of the negative pressure water box, so that the EER of the system is unstable at $50 \sim 75^{\circ} \mathrm{C}$, and the EER of the system drops significantly when it is higher than $\left.75^{\circ} \mathrm{C} ; 3\right)$ Choosing a low temperature heat pipe will reduce the evaporation temperature of the thermal fluid, To promote the heat transfer of the hot air to the vacuum box through the heat pipe.

In summary, the air flow status, insufficient vacuum of the negative pressure water tank and the evaporation temperature of the heat pipe fluid will affect the working performance of the refrigerator.

\section{Conclusion}

In order to study the feasibility and performance of negative pressure water evaporative air conditioning, a heat pipe air conditioning system test bench based on the latent heat of water evaporation was built to measure the cooling capacity and energy efficiency ratio of the system under $30 \sim 85^{\circ} \mathrm{C}$ air inlet conditions. Combined with simulation verification, the following conclusions are obtained:

(1) In the temperature range of $30 \sim 50^{\circ} \mathrm{C}$, the refrigerating capacity and energy efficiency ratio gradually increase with the increase of working temperature; in the temperature range of $50 \sim 75^{\circ} \mathrm{C}$, the system reaches the high efficiency working range; after $75^{\circ} \mathrm{C}$, the refrigerating capacity and energy efficiency ratio decrease due to insufficient negative pressure of vacuum pump.

(2) The results show that the refrigeration effect is better in the high efficiency working range of $50 \sim 75^{\circ} \mathrm{C}$. The maximum cooling capacity is $376 \mathrm{~W}$ and the energy efficiency ratio is 2.5. When the refrigerator is used in the temperature range of $30 \sim$ $40^{\circ} \mathrm{C}$, the EER of the system is 1.4 and the refrigerating capacity is $221.6 \mathrm{~W}$. The heat pipe air conditioning system basically achieves the design index of EER of 2.1 and cooling capacity of $298 \mathrm{~W}$ at $40^{\circ} \mathrm{C}$.

(3) The factors influencing the difference between experimental data and design index are air flow, vacuum degree of negative pressure water tank, high evaporation temperature of heat conduction liquid in heat pipe.

(4) When the negative pressure water evaporative cooling unit is put into practical application, increasing the extraction capacity of vacuum pump, reducing the evaporation temperature of heat pipe and enhancing the turbulence degree of the flow field in the bellows will be the important ways to improve the performance of the device.

\section{References}

[1] Li Liansheng. Research progress and development trend of refrigerant replacement technology[J]. Journal of Refrigeration, 2011, 32(6):57-62.

[2] Yang Jiankun, Zhang Xu, Xu Lin, et al. Numerical simulation of air distribution in evaporative cooling air-conditioned rooms[J]. Building Energy \& Environment, 2004, 23(3):16-19.

[3] Zheng Zongda, Zhang Jian, Chen Jie, et al. Numerical simulation analysis of the performance of direct evaporative cooling air conditioning [J]. Building Energy Efficiency, 2013(10):13-17. 
[4] Guo Xinchuan, Zhao Xugui. Factors affecting the performance of evaporative cooling heat exchangers[J]. Journal of Tianjin University, 1996, 29(4):569-572.

[5] Zhang Longai, Ren Chengqin, Ding Jie, et al. CFD method and three-dimensional numerical simulation of indirect evaporative cooling heat exchanger[J]. Refrigeration and Air Conditioning, 2005(4):18-23.

[6] Zhang Longai,Ren Chengqin. Numerical simulation of heat transfer performance of indirect evaporative cooling plate heat exchanger[J]. Refrigeration Air Conditioning \& Electric power Machinery, 2005, 26(5):6-9,42.

[7] Fakhrabadi F. Kowsary K.,Optimal design of a regenerative heat and mass exchanger for indirect evaporative cooling[J]. Applied Thermal Engineering, 2016,102:1384-1394.

[8] Ji Shifu, Yu Xia, Wang Wen,et al.Experimental study of indirect evaporative cooling for fresh air pre-cooling of air conditioners[J].Heating Ventilating \& Air Conditioning,2006,36(4):102-104.

[9] ZHANG Jianzhong. Application of evaporative refrigeration and air conditioning system in college student activity center of ningxia university[J]. Heating \& Refrigeration, 2007(6):42-43.

[10] Li Weiyi,Guo Qiang, Liu Yi, et al. Development of new environmentally friendly energy-saving evaporative refrigeration brand new home air conditioning technology[J]. Shanxi Architecture, 2015(23):115-116,117.

[11] Wang Fei, Wang Jun, Shi Zuojun, et al. Design and analysis of heat-pipe computer room air conditioning system[J]. Refrigeration and Air-conditioning, 2018, 18(5):4-8.

[12] Deng Dong, Cheng Jiangping, Zhang Shengchang, et al. Theoretical and experimental validation study on automotive air-conditioning based on heat pipe and LNG cold energy for LNG-fueled heavy vehicles[J]. Heat and Mass Transfer, 2017,53(8):2551-2558.

[13] Xing Yongjie, Liu Fang. Application of evaporative cooling technology in air conditioning energy saving[J]. New Energy Sources,2000,22(12):134-137.

[14] Sun Wenchao, Qian Ronghua. Natural energy utilizing heat pipe air conditioners[C].Proceedings of the 2017 China Communications Energy Conference.Beijing: Communication Power Committee of the China Communications Society, 2017:170-171.

[15] Xie Siyuan; Liu Weijun;Song Kaiyun,et al.Reliability verification of COMSOL simulation measurement of thermal conductivity of multilayer composite board [J].Industry and Technology Forum, 2020, 19(4):47-49. 